\title{
LINGUAGEM ESCRITA E SUBJETIVIDADE: IMPLICAÇÕES DO TRABALHO GRUPAL
}

\section{Writing language and subjective quality: implications of group work}

\author{
Maria Letícia Cautela de Almeida Machado ${ }^{(1)}$, Ana Paula Berberian ${ }^{(2)}$, Ana Paula Santana ${ }^{(3)}$
}

\section{RESUMO}

Tema: linguagem escrita e subjetividade no grupo fonoaudiológico. Procedimentos: este relato de caso tem por objetivo analisar como sujeitos, que participam de um grupo fonoaudiológico, significam suas histórias com a linguagem escrita e como tal grupo pode constituir-se como um espaço para a ressignificação de tais histórias. O material do estudo clínico foi coletado a partir do atendimento grupal envolvendo nove adolescentes, inseridos no Ensino Fundamental da Rede Pública de Curitiba, encaminhados pela escola para tratamento fonoaudiológico, com queixa de distúrbio de leitura e escrita. Tal atendimento foi realizado, durante um ano, na Clínica Fonoaudiológica da Universidade Tuiuti do Paraná. Os encontros eram semanais, com duração de duas horas, totalizando 48 sessões. A coleta de dados foi realizada a partir de vídeo-gravações e do registro diário das sessões. Foram selecionados seis episódios considerados significativos para a análise da temática. Resultados: a pesquisa indicou que os sujeitos estabeleciam uma relação de sofrimento com a escrita a partir da qual assumiam uma posição de incompetência em ler e escrever. A partir do processo terapêutico foi possível ressignificar as relações dos adolescentes com essa modalidade de linguagem, de forma que puderam assumir diferentes posições e um lugar de autoria e de interlocutor capaz. Conclusão: o grupo fonoaudiológico construiu-se como um espaço de troca para que os sujeitos estabelecessem uma relação significativa com a leitura e a escrita, propiciando condições fundamentais para a ressignificação dos sintomas e para a interação com diversos textos escritos, promovendo, assim, mudanças na relação do sujeito com sua linguagem.

DESCRITORES: Linguagem; Desenvolvimento da Linguagem; Escrita Manual

\section{INTRODUÇÃO}

Pesquisas e opiniões do senso comum apontam dificuldades, por parcela significativa da população brasileira, com relação à apropriação e ao uso da linguagem escrita. Ainda que, na maioria dos casos, essas dificuldades tenham sido produzidas

(1) Fonoaudióloga da Secretaria Municipal de Saúde do Rio de Janeiro, Rio de Janeiro, RJ; Mestre em Distúrbios da Comunicação pela Universidade Tuiuti do Paraná; Doutoranda em Educação pela Universidade Estadual do Rio de Janeiro.

(2) Fonoaudióloga; Docente do Programa de Mestrado e Doutorado em Distúrbios da Comunicação da Universidade Tuiuti do Paraná, UTP, Tuiuti, PR; Doutora em História pela Pontifícia Universidade Católica de São Paulo.

(3) Fonoaudióloga; Docente do Programa de Mestrado e Doutorado em Distúrbios da Comunicação da Universidade Tuiuti do Paraná, UTP, Tuiuti, PR; Doutora em Linguística pela Universidade Estadual de Campinas.

Conflito de interesses: inexistente por fatores sociais, escolares ou familiares, o fato é que os sintomas de leitura e escrita revelam que os sujeitos estabelecem uma relação de sofrimento com essa modalidade de linguagem ${ }^{1}$. Tal realidade está associada à resistência e ao desprazer na relação com a escrita, ao desconhecimento acerca de suas funções, valores e usos, bem como a formas restritas de operar com a leitura e escrita. Enfim, a relação negativa que os sujeitos estabelecem com a linguagem escrita implica sentimentos de incompetência, de ignorância e de inferioridade que restringem as possibilidades de seu uso ${ }^{2-4}$.

Dessa forma, a intervenção fonoaudiológica, nesses casos, deve incluir como meta a reconstrução de uma relação significativa do sujeito com a linguagem escrita, apreendida como prática constitutiva do sujeito e, portanto, como mediadora das relações sociais ${ }^{2,4}$. Nessa direção, a terapêutica grupal, vem sendo apontada como uma abordagem que, potencialmente, pode favorecer o implemento 
de práticas significativas da linguagem escrita e, portanto, de ressignificação de histórias de sofrimento com essa modalidade de linguagem ${ }^{4,5}$.

Pode-se acompanhar, atualmente ${ }^{4-13}$, um implemento em pesquisas no campo da Fonoaudiologia que buscam formular subsídios teórico-metodológicos para uma análise das particularidades que envolvem a organização e a constituição dos grupos e de suas potencialidades terapêuticas. $O$ grupo terapêutico fonoaudiológico vem, gradativamente, solidificando-se e, de uma iniciativa que visava ampliar o número de sujeitos atendidos para dar conta da demanda do Sistema Público de Saúde ${ }^{6}$, passou a ser considerado uma possibilidade efetiva de construções coletivas, que podem proporcionar o desenvolvimento (individual e social) dos sujeitos ${ }^{7-13}$.

Levando em conta que os sujeitos com queixa de leitura e de escrita apresentam, muitas vezes, condições de leitura e de escrita consideradas restritas - especialmente em decorrência de experiências de letramento e dos processos de escolaridade a que estão submetidos ${ }^{14,15}$, sinaliza-se que, ao decidir pelo atendimento clínico grupal desses sujeitos, identifica-se no processo clínico terapêutico uma possibilidade de ressignificação dos sentidos atribuídos à queixa ${ }^{4,5}$. A partir da constatação de que, na maioria dos casos, as dificuldades de leitura e de escrita são justificadas por deficiências inerentes ao sujeito ${ }^{2,3,14,15}$, considera-se a necessidade de que tal crença seja ressignificada, como condição para que ocorram mudanças na relação do sujeito com sua linguagem e nas suas condições de letramento $2,4,5$.

Objetiva-se, no grupo, construir com os sujeitos, fortemente marcados pelo estatuto da incapacidade, possibilidades de desestabilizarem verdades estigmatizadas e de resgatarem as condições de apropriação dessa modalidade de linguagem, na qual os sujeitos estiveram e estão inseridos ${ }^{4,5}$. Parte-se do entendimento, com base nas posições de Bakhtin ${ }^{16}$, de que os processos de apropriação da escrita realizam-se conforme as condições materiais e subjetivas que concorrem para a qualidade e natureza das relações sociais intermediadas por essa modalidade de linguagem.

Ressalta-se que a terapêutica grupal difere da individual tendo em vista a possibilidade do jogo interacional entre os participantes do grupo, entre pares e não apenas entre terapeuta e paciente. Entretanto, para a constituição da grupalidade é preciso o estabelecimento de um enquadre que viabilize a construção de relações entre seus membros e a possibilidade de uma escuta significativa. Além disso, o grupo terapêutico deve viabilizar situações em que seus componentes flexibilizem papéis e posicionamentos, permitindo novas possibilidades de estar nas relações ${ }^{4,5}$.

Assim, esta pesquisa tem por objetivo analisar como sujeitos, que participam de um grupo terapêutico fonoaudiológico, significam as suas histórias com a linguagem escrita e como tal grupo pode constituir um espaço para a ressignificação de tais histórias.

\section{APRESENTAÇÃO DO CASO}

O material do estudo clínico foi coletado a partir do atendimento de um grupo de nove adolescentes, inseridos na $5^{\mathrm{a}}$ e $6^{\mathrm{a}}$ série do Ensino Fundamental da Rede Pública de Curitiba, encaminhados pela escola para tratamento fonoaudiológico com queixa de distúrbio de leitura e escrita. Tal atendimento foi realizado, durante um ano, na Clínica Fonoaudiológica da Universidade Tuiuti do Paraná. Os encontros eram semanais, com duração de duas horas, totalizando 48 sessões. Os adolescentes foram representados pelas letras: $A B, J E, J K, M S, N I, R A$, ST, VI e WR e a terapeuta pela letra TP.

A intervenção fonoaudiológica grupal foi conduzida a partir dos seguintes pressupostos teórico-metodológicos: 1 - da abordagem do grupo como um espaço social composto por sujeitos com necessidades e objetivos comuns, o que remete a uma condição de pertencimento e de continência; 2 - do estabelecimento de uma escuta terapêutica grupal, a partir do estabelecimento de relações que coloquem todos sujeitos no papel de sujeitos/interlocutores; 3 - do estabelecimento de projetos e atividades de interesse comum, em torno de práticas significativas de leitura e escrita que garantam a todos a possibilidade de assumir posições de autoria; 4 - da flexibilização de papéis, que resultassem na desarticulação de estruturas, mecanismos e papéis estereotipados.

A coleta de dados foi realizada a partir de vídeogravações e do registro diário das sessões. As gravações foram transcritas seguindo as normas apresentadas por Marcuschi ${ }^{17}$ e foram selecionados seis episódios para a análise, referentes ao início, meio e final do processo terapêutico, conforme descrito nos resultados.

Essa pesquisa foi aprovada pelo Comitê de Ética em Pesquisa da Universidade Tuiuti do Paraná CEP-UTP 028/2005, sendo realizada após a assinatura do Termo de Consentimento Livre e Esclarecido pelos pais e/ou responsáveis dos sujeitos envolvidos.

Para a análise qualitativa dos episódios foram adotadas as diretrizes da análise microgenética e da abordagem sócio-histórica acerca do grupo terapêutico e da linguagem ${ }^{18}$. 


\section{RESULTADOS}

Episódio I (relato oral - sessão 6)

Esse episódio apresenta dados referentes ao diálogo estabelecido com e entre os adolescentes em torno da seguinte questão: Por que estamos aqui?

1.JE: Só estou aqui porque tenho problema.

2. TP: Problema? Que problema?

3. WR: Eu falo rápido, certo, mas escrevo errado.

4. MS: Não gosto muito de ler, é por isso que estou aqui.

5. TP: Está aqui porque não gosta de ler.

6. MS: Porque é para passar de ano.

7. RA: Eu escrevo errado.

8. TP: Escreve errado, como assim?

9. RA: Troco letra.

10. JK: Eu confundo "p" com "b", sempre confundo.

11. NI: Palavras com "s", "ss", sei lá.

12. JE: Eu erro quando a palavra é muito comprida. Não sei palavras grande, complicadas.

13. TP: Vocês estão preocupados com algumas coisas na hora de escrever: trocas de "p" e "b", "m" e "n", algumas palavras são compridas tanto para falar quanto para escrever. Ficam angustiados porque acham que não sabem, tem dificuldade.

Episódio II (relato oral - sessão 8)

Tal episódio derivou de uma proposta na qual os adolescentes deveriam escrever num papel duas palavras que eles achavam que tinham dificuldade em escrever de acordo com a norma e duas palavras que achavam que não tinham. Em seguida cada um iria ler as palavras e explicar o porquê das escolhas. Seguem, abaixo, alguns trechos da discussão:

1. TP: O que vocês acharam mais difícil pensar, a palavra que tem dificuldade ou a palavra que não tem dificuldade?

2. WR: Que tem dificuldade.Tenho dificuldade é no "m" e "n", o "r" de "brincar" e o "t".

3. TP: Engraçado porque você escreveu certo no papel.

4. ST: A palavra é "óculus", eu fico na dúvida se escreve "óculos" ou "óculus".

5. TP: Você está dizendo que fala "óculus" e na hora de escrever fica na dúvida porque a gente fala de um jeito e na hora de escrever, escreve de outro.
6. TP: VI escreveu que tem dificuldade em "professor" e "passar".

7. VI: É que eu confundo se é "s" ou "ss".

8. MS: É igual "passarinho".

9. TP: Isso todo mundo confunde. Por que você acha que confunde?

10. VI: Porque eu não sei escrever.

11. TP: Como não sabe escrever? E esse texto aqui, quem escreveu?

12. VI: Fui eu.

13. TP: O que acontece é que existem palavras que se escreve com "s", "ss", "ç", "c" e tudo se lê da mesma maneira. E a gente precisa decidir que letra usar para escrever aquela palavra.

14. TP: RA escreveu que tem dificuldade na palavra cachecol. Qual é a dificuldade?

15. RA: É que às vezes a professora diz uma coisa e eu escrevo outra. Eu penso que entendo só que eu não entendo.

16. TP: Por que você acha que não entende?

17. RA: Não sei.

18. TP: É o som e a letra, né?

19. TP: Nós vimos alguns exemplos de palavras que vocês achavam que tem dificuldade, novamente apareceram algumas letras, algumas letras se repetiram "m" e "n", "u" e "l", "s" e "ss", "r". São dificuldades, na verdade, que todos nós temos em alguns momentos. Todo mundo tem momentos que escreve com dificuldade e outros que escreve sem nenhuma dificuldade. Eu não vejo problema nenhum nisso. Tem momentos que eu escrevo que eu também não sei com que letra se escreve e tem outras coisas que eu já superei. O importante é que o outro entenda o que a gente escreveu, né?

Episódio III (relato oral - sessão 9)

Numa sessão em que os adolescentes estavam envolvidos numa produção textual surgiram perguntas sobre como deveriam escrever algumas palavras. Nesse contexto a terapeuta propôs para os adolescentes escreverem algumas palavras e depois perguntou para eles como cada um escreveu e porque eles acham que escreveram daquela maneira. Segue algumas respostas, elaboradas pelos adolescentes, na interlocução abaixo:

1. TP: Porque você acha que escreveu essa palavra assim?

2. NI: Porque não estava prestando atenção.

3. TP: Então está bem, vamos todos prestar bastante atenção e eu vou dizer outras palavras para vocês escreverem. 
4. TP: Está todo mundo prestando atenção? Então porque você acha que a troca apareceu do mesmo jeito? Será que tem a ver com prestar atenção?

5. VI: É porque eu sou burro mesmo.

6. TP: Então você acha que todo mundo é burro porque quase todo mundo já trocou ou ainda troca essas letras.

7. JK: Então é porque a gente não lembra.

8. TP: A questão aqui é que não se escreve do modo como se fala e muitas vezes apoiamos nossa escrita na maneira como falamos. /... /

Episódio IV (relato oral - sessão 12)

Esse episódio trata-se de uma atividade na qual cada integrante do grupo escolheu um fato marcante de sua vida que quisesse contar para o grupo. Ressaltamos que sete adolescentes referiram episódios de vivências em família, em geral, marcadas por situações de sofrimento. Dois adolescentes relataram como fato marcante a sua participação no grupo. Trazemos, a seguir, o relato de um desses participantes do grupo: aqui.

1. JE: Uma coisa boa que eu gosto muito é vir

2. TP: Por que é importante vir aqui para você?

3. JE: Porque eu gosto bastante daqui. Porque é legal. Como a minha professora disse, eu tenho dificuldade mas a gente se esforça assim, né. Quando eu não tenho lição para casa eu pergunto: Oh, professora, não tem um livrinho para eu ler.

4.TP: Eu entendi uma coisa que a JE falou: que você quer aprender mais. Você acha que esse espaço é importante porque é uma oportunidade para você.

5. JE: É, eu não tou tão mal, ainda dá para me recuperar.

6. TP: Você acha que a pessoa que quer crescer tem que estar mal?

\section{Episódio V (relato escrito - sessão 20)}

Nesse episódio o grupo finaliza o projeto de elaboração de um jornal que vinham realizando ao longo de dez sessões, escrevendo algo a respeito deles para seus leitores. A seguir, apresentamos alguns desses relatos escritos:

1. ST: Eu adoro estudar e acho que estudar é fundamental para nossa vida. Adoro desenhar e quando eu crescer quero virar estilista. Eu amo a minha família, os meus amigos do grupo e todos que me ajudaram no jornal. Leia nosso jornal para relaxar, você gostará muito!

2. AB: Eu gosto de escrever e de fazer poesias. Gosto de fazer natação e de computação. Leia nosso jornal porque você pode aprender receitas, jogos, brincadeiras e tudo mais.

3. JK: Tenho muitas amigas. Eu amo estudar! Tenho muito gosto por tudo o que fiz no jornal, penso em algum dia fazer outro jornal. Eu indico a leitura do nosso jornal como passa-tempo.

Episódio VI (relato escrito - sessão 45)

Esse episódio apresenta mensagens escritas por alguns dos integrantes do grupo para os leitores dos livros que elaboraram para a biblioteca da clínica de fonoaudiologia que frequentavam. Tais mensagens foram inseridas na capa do livro de cada membro do grupo.

1. JE: Eu estou muito feliz por ter feito esse livro. Eu espero que você goste. Leia para aprender que todo mundo pode fazer que nem eu!

2. MS: Leia esse livro para dar risada.

3. NI: Leia esse livro para você aprender mais histórias.

4. WR: Leia esse livro porque ele tem coisas muito legais!

5. RA: Leia com carinho porque ele foi feito com muita dedicação.

\section{DISCUSSÃO}

No episódio I, a partir da interlocução que foi se estabelecendo entre os sujeitos, dificuldades e expectativas foram emergindo, evidenciando o fato de as dificuldades não serem de um só sujeito, mas compartilhadas por todos. Reconhecer o que é comum ao grupo e ao mesmo tempo como o comum se materializa de forma particular gerou um sentimento de pertencimento entre os adolescentes. A demanda dos adolescentes em torno das dificuldades com a linguagem escrita, que na escola, em geral, resulta numa condição de exclusão e de incapacidade, no grupo é o que de alguma forma inclui os adolescentes, ou seja, garante a ele uma possibilidade de compartilhar suas experiências e fazer parte de um grupo ${ }^{4,5}$. Por conta disso, o grupo foi, gradativamente, se constituindo como um espaço em que cada adolescente pode ser aceito em suas dificuldades e possibilidades e, por conta disso, as relações passam a ser permeadas por uma atitude de continência. A mediação do terapeuta no sentido de criar um contexto em que os adolescentes puderam reconhecer e explicitar suas limitações e possibilidades pode ser evidenciada, por exemplo, no episódio I (turnos 2, 8 e 13) e no episódio II (turnos $3,5,9,11$ e 13) quando a terapeuta, lança ao grupo questionamentos, desestabilizando noções e posições dos adolescentes como incompetentes, desatentos, esquecidos, ignorantes. O processo de ressignificação das dificuldades como parte do 
processo de apropriação de leitura e escrita e das condições de domínio dessa modalidade de linguagem que tais adolescentes estão expostos foram sendo ressignificadas durante o processo terapêutico grupal.

Os episódios II e III evidenciam interlocuções em que os adolescentes explicitam sentidos atribuídos à queixa e a terapeuta intervem na busca de novas possibilidades de entendimento e análise em relação aos mesmos. Explicações formuladas pelos adolescentes em relação ao fato de apresentarem manifestações ortográficas fora do padrão evidenciam uma visão restrita dos motivos que os levam a tais produções, como por exemplo, "Porque eu não sei escrever" (episódio II, turno 10); "É que às vezes a professora diz uma coisa e eu escrevo outra. Eu penso que entendo só que eu não entendo" (episódio II, turno 15); "Porque não estava prestando atenção" (episódio III, turno 2); "É porque eu sou burro mesmo" (episódio III, turno 5); "É porque a gente não lembra" (episódio III, turno 7). Os adolescentes atribuem às dúvidas quanto aos aspectos ortográficos da língua, a dificuldades ligadas à inteligência, ao comportamento, à percepção ou à memória. A restrição de tais formulações devese à crença de que o problema está relacionado a alguma falha pessoal, eles consideram o erro como um problema individual, fruto de uma inabilidade, de um distúrbio ou de uma deficiência intrínseca ${ }^{2,3}$, desconsiderando assim as condições materiais e subjetivas que participam de forma decisiva no processo de apropriação da linguagem escrita, inclusive da ortografia ${ }^{14,15}$.

Contrapondo essa visão, hegemonicamente, veiculada no contexto educacional, coube à terapeuta oferecer elementos e experiências que permitissem aos adolescentes compreender que manifestações ortográficas fora do padrão fazem parte do processo de apropriação da escrita e que a manutenção das mesmas evidencia limitações no processo de ensino-aprendizagem (episódio II, turnos 5, 13, 18 e 19 e episódio III, turnos 4, 6 e 8). Gradativamente os adolescentes passaram a considerar que hipóteses sobre a escrita, mesmo que fora do padrão, não revelam uma falta de conhecimento, pelo contrário, revelam elaborações, associações, enfim, a construção do conhecimento acerca da escrita 2,3,14,15.

No episódio IV, o fato mencionado pelo adolescente como marcante de sua vida foi participar do grupo. Nessa situação, JE afirma gostar de vir ao grupo, pois nesse contexto pode lidar com e superar suas dificuldades. A terapeuta devolve a JE suas colocações, acrescentando a ideia de que ela quer melhorar, enfim, explicita o seu desejo de avançar em seu processo. Tal desejo é condição para que
JE assuma lugar de leitor e escritor (episódio IV, turno 4).

Pode-se identificar no discurso de JE, visões recorrentemente formuladas no contexto escolar, enfim, de que ela tem dificuldade, mas é esforçada (episódio IV, turno 3). Tal posição parece ter sido incorporada por JE, estando relacionada à construção de sua linguagem e sua queixa ${ }^{1,4}$. Objetivando desestabilizar tal posição a terapeuta aponta outras possibilidades de significações.

No discurso de JE há uma ambiguidade, pois se afirma ter dificuldades (episódio IV, turno 3), refere também que não está tão mal assim (episódio IV, turno 5). O discurso de JE revela que a mesma está na fronteira de duas posições distintas: 1) Como alguém que tem dificuldade, mas se esforça, ou seja, uma possibilidade de entendimento de que quanto mais ela se esforçar mais ela vai conseguir; como se o problema fosse apenas dela, de se esforçar ou não se esforçar, então talvez antes ela não se esforçasse mas agora ela se esforça; 2) Como alguém que reconhece que afirma "não estou tão mal assim" (episódio IV, turno 5). Quando ela não tem lição de casa, quando não tem que atender às expectativas da escola, quando não tem que fazer aquilo que é só a lição da escola, então ela pede para ler um livro (episódio IV, turno 3). O livro já aparece aqui como alguma coisa que the dá prazer, que também está ligado ao aprender. Nota-se, então, como JE já pode desenvolver práticas de leitura significativas.

O grupo, dessa forma, apresenta-se como uma possibilidade de atender as necessidades de JE. Ela percebe uma dificuldade e tem o desejo de fazer algo para superá-la, depositando no grupo uma confiança e uma expectativa de que as relações estabelecidas nele possam atender às suas necessidades. Ressalta-se que à demanda da escola em relação ao desempenho de JE na leitura e escrita, está associada a sua condição de sujeito não só na escola, mas na vida ${ }^{4}$.

Pode-se observar a terapeuta explicitando e valorizando as reflexões de JE quando diz: "eu entendi uma coisa que a JE falou, que você quer aprender mais e que você acha que esse espaço é importante porque é uma oportunidade para você" (episódio IV, turno 4). A terapeuta buscando desestabilizar a noção de incompetência, muitas vezes, referida por JE, questiona os motivos que a levam querer aprender e crescer ao perguntar: "Você acha que a pessoa que quer crescer tem que estar mal?" (episódio IV, turno 6). Enfim, leva JE a refletir se: quer crescer para corresponder uma expectativa da escola, porque você acha que está mal ou se ela quer crescer porque quer ser um sujeito com mais autonomia, com mais possibilidades. 
A partir das reflexões referentes aos episódios I, II, III e IV, fica evidente que foi se constituindo no grupo o desejo comum de sair de uma posição de incapacidade para uma posição que permitisse o estabelecimento de relações significativas de leitura e escrita ${ }^{4}$.

As noções de "poder fazer algo", de "eu não estou tão mal assim, eu posso me recuperar" (episódio IV, turno 5), enfim, de se considerar capaz, foi sendo constituída no contexto grupal conforme apresentado nos episódios V e VI, nos discursos de JK: "Tenho muito gosto por tudo o que fiz no jornal, penso em algum dia fazer outro jornal" (episódio $V$, turno 3) e de JE: "Eu estou muito feliz por ter feito esse livro. Leia para aprender que todo mundo pode fazer que nem eu" (episódio VI, turno 1).

Nos episódios V e VI também fica evidente que os adolescentes incorporaram os diferentes usos e funções da escrita e não mais a associam apenas aos deveres da escola, o que pode ser apreendido quando ST refere: "Leia nosso jornal para relaxar, você gostará muito!" (episódio V, turno 1), ou quando $A B$ escreve: "Leia nosso jornal porque você pode aprender receitas, jogos, brincadeiras e tudo mais." (episódio V, turno 2) ou, ainda, quando MS refere: "Leia esse livro para dar risada" (episódio VI, turno 2).

O grupo constituiu-se, portanto, não apenas como um espaço propício ao desenvolvimento da linguagem como também à ressignificação de histórias de sofrimento com a linguagem escrita $1,4,5$, conforme as colocações "Eu estou muito feliz por ter feito esse livro" (JE, episódio VI, turno 1) ou ainda
"Leia com carinho porque ele foi feito com muita dedicação" (RA, episódio VI, turno 5).

Um dos fatores que contribuíram para essa mudança de posição foi a possibilidade de participação dos adolescentes em práticas efetivas e significativas de leitura e escrita ${ }^{4,5}$, bem como os diálogos estabelecidos no grupo, processos favoráveis não apenas ao desenvolvimento da linguagem, como da própria subjetividade ${ }^{7-12}$.

\section{CONCLUSÃO}

O estudo de caso apontou para o fato de que os chamados quadros de distúrbios de leitura e escrita, via de regra, envolvem não apenas sintomas de escrita, mas também, sintomas de natureza subjetiva. A partir de tal pressuposto buscou-se evidenciar a importância da terapia fonoaudiológica priorizar a ressignificação da relação do sujeito com a linguagem escrita. Ressalta-se, ainda, que a abordagem terapêutica grupal contribuiu para a ressignificação de histórias de sofrimento com a linguagem escrita, desestabilizando verdades estigmatizadas e reinterpretando condições de domínio dessa modalidade de linguagem, a partir das quais os sujeitos, fortemente marcados pelo estatuto da incapacidade, estão inseridos.

A ressignificação dos sintomas contribuiu para a compreensão de que a restrição em relação ao acesso e ao uso da linguagem escrita compartilhada pelos adolescentes estava articulada às desiguais e distintas condições de escolaridade, de letramento e, portanto, de formação para o exercício da cidadania.

\section{ABSTRACT}

Background: written language and subjectivity in a speech language therapy group. Procedures: this paper aims to analyze how individuals that participate in a speech language therapy group, signify their stories by using the written language and how this process can constitute an opportunity to recreate their meanings. The data for this clinical study was collected in a group therapy involving 9 teenager students from public schools of Curitiba, with the complaint of reading and writing disorders. The group therapy was realized during one year inside the Speech language therapy clinic in Tuiuti University of Paraná. The meetings occurred every week during two hours totalizing 48 meetings. All data were video recorded and also written in a session diary. Six episodes considered very expressive were selected in order to analyze this theme. Results: the research indicated that these individuals had a suffering relation with the written language and that they assumed incapacity positions towards it. It could be possible to observe that the clinical practices inside the group helped to recreate these relations, so that the individuals began to feel capable and assume responsibility positions in reading and writing practices. Conclusion: the speech language therapy group was built as a place where the individuals could set up a significant relation with reading and writing, providing key conditions for the re-significance of the symptoms and for interacting with different written texts, promoting thus changes between the individual and his own language.

KEYWORDS: Language; Language Development; Handwriting 


\section{REFERÊNCIAS}

1. Garcia ALM. Fonoaudiologia e letramento. In: Dauden ATBC, Mori-de Angelis CC, organizadores. Linguagem escrita: tendências e reflexões sobre o trabalho fonoaudiológico. São Paulo: Pancast; 2004. p.15-35.

2. Massi GA, Berberian AP. A clínica fonoaudiológica voltada aos chamados distúrbios de leitura e escrita: uma abordagem constitutiva da linguagem. Rev Soc Bras Fonoaudiol. 2005; 10(1):43-52.

3. Massi GA. Dislexia ou processo de aquisição da escrita? Dist Comun. 2004; 16(3): 355-69.

4. Machado MLCA. Grupo de linguagem escrita: uma proposta de intervenção fonoaudiológica. [dissertação]. Curitiba (PR): Universidade Tuiuti do Paraná; 2007.

5. Machado MLCA, Berberian AP, Massi G. A terapêutica grupal na clínica fonoaudiológica voltada à linguagem escrita. In: Santana AP, Berberian AP, Guarinello AC, Massi G, organizadores. Abordagens grupais em fonoaudiologia: contextos e aplicações. São Paulo: Plexus; 2007. p. 58-79.

6. Correa MB. Considerações sobre terapia de grupo na clínica fonoaudiológica. In: Lier De Vitto MF, organizador. Fonoaudiologia: no sentido da linguagem. 2. ed. São Paulo: Cortez; 1997. p.39-48. 7. Panhoca I, Penteado RZ. Grupo terapêutico-fonoaudiológico: a construção (conjunta) da linguagem e da subjetividade. Pró-Fono. 2003; 15(3):259-66.

8. Barbetta NL, Panhoca I. Gêmeos idênticos no grupo terapêutico-fonoaudiológico: a construção da linguagem e da subjetividade. Pró-Fono. 2003; 15(2):139-48.

9. Barbetta NL, Panhoca I, Zanolli ML. O grupo familiar como a raiz da constituição da linguagem e da identidade de gêmeos monozigóticos: ensaios preliminares. In: Revista da Sociedade Brasileira de Fonoaudiologia. 2004; Suplemento especial: XII Congresso Brasileiro de Fonoaudiologia; Out 6-9; 2004.

10. Freitas AP, Camargo EAA, Panhoca I, Monteiro MIB. O processo de construção da identidade e da subjetividade no grupo terapêuticofonoaudiológico. In: Revista da Sociedade Brasileira de Fonoaudiologia 2004; Suplemento especial: XII Congresso Brasileiro de Fonoaudiologia; Out 6-9; 2004.

11. Panhoca I, Camargo EAA, Freitas AP, Monteiro MIB. O grupo terapêutico - fonoaudiológico e o processo de construção da identidade e da subjetividade. Fono Atual. 2005; 8(31):53-9.

12. Penteado RZ, Panhoca I, Siqueira D, Romano FF, Lopes P. Grupalidade e família na clínica fonoaudiológica: deixando emergir a subjetividade. Rev Dist Comun. 2005; 17(2):161-71.

13. Panhoca I. Grupo terapêutico-fonoaudiológico: aprofundando um pouco mais as reflexões. Dist Comun. 2007; 19(2):257-62.

14. Guarinelo AC, Berberian, AP, Santana AP, Massi GA, Rivabem KD, Jacob LCB, et al. Dificuldades de aprendizagem da escrita: uma análise de acompanhamentos clínicos dessa modalidade de linguagem. Rev Letras. 2006; 70:247-66.

15. Guarinelo AC, Massi GA, Berberian AP, Rivabem $K D$. A clínica fonoaudiológica e a linguagem escrita: estudo de caso. Rev. CEFAC. 2008; 10(1):38-44. dx.doi.org/10.1590/S1516-18462008000100006

16. Bakhtin M. Marxismo e filosofia da linguagem. 7. ed. São Paulo: Hucitec; 1995.

17. Marcuschi LA. Análise da conversação. São Paulo: Ática; 2003.

18. Góes MCR. A abordagem microgenética na matriz histórico-cultural: uma perspectiva para o estudo da constituição da subjetividade. Cad CEDES. 2000; 20(50):9-25.

RECEBIDO EM: 01/12/2008

ACEITO EM: 05/07/2009

Endereço para correspondência

Maria Letícia Cautela de Almeida Machado

Rua Leite Leal, 135 ap. 201 Bloco 1

Rio de Janeiro - RJ

CEP: 22240-100

E-mail: maria_leticia2005@ hotmail.com 